\title{
Subgrouping of risky behaviors among Iranian college students: a latent class analysis
}

\author{
This article was published in the following Dove Press journal: \\ Neuropsychiatric Disease and Treatment \\ 22 July 2016 \\ Number of times this article has been viewed
}

\author{
Saeid Safiri ${ }^{1,2}$ \\ Afarin Rahimi-Movaghar ${ }^{3}$ \\ Masud Yunesian ${ }^{4,5}$ \\ Homayoun Sadeghi- \\ Bazargani ${ }^{6}$ \\ Mansour Shamsipour ${ }^{5}$ \\ Mohammad Ali Mansournia' \\ Akbar Fotouhi' \\ 'Department of Epidemiology \\ and Biostatistics, School of Public \\ Health, Tehran University of Medical \\ Sciences, Tehran, ${ }^{2}$ Department of \\ Public Health, School of Nursing and \\ Midwifery, Maragheh University of \\ Medical Sciences, Maragheh, ${ }^{3}$ Iranian \\ National Center for Addiction \\ Studies (INCAS), Iranian Institute for \\ Reduction of High-Risk Behaviors, \\ Tehran University of Medical Sciences, \\ Tehran, ${ }^{4}$ Department of Environmental \\ Health Engineering, School of Public \\ Health, ${ }^{5}$ Department of Research \\ Methodology and Data Analysis, \\ Institute for Environmental Research, \\ Tehran University of Medical Sciences, \\ Tehran, ${ }^{6}$ Road Traffic Injury Research \\ Center, Department of Statistics \& \\ Epidemiology, Tabriz University of \\ Medical Sciences, Tabriz, Iran
}

Correspondence: Akbar Fotouhi Department of Epidemiology and Biostatistics, School of Public Health, Tehran University of Medical Sciences, Enghelab Sq., Pour Sina Street, PO Box 14I55-6446, Tehran, Iran Email afotouhi@tums.ac.ir
Background: Risky behaviors may interrupt development or cause considerable morbidity or mortality. This study's purpose was to determine subgroups of students based on risky behaviors and assess the prevalence of risky behaviors in each of the subgroups.

Participants and methods: This anonymous cross-sectional study was carried out in October 2015 and November 2015, with 1,777 students from Tabriz University of Medical Sciences, through multistage random sampling method. The data were analyzed by latent class analysis. Results: The prevalence rates of cigarette smoking (more than or equal to ten cigarettes), hookah use ( $\geq 1$ time/month), and alcohol consumption ( $\geq 1$ time/month) during the last year were $12.4 \%$ (95\% confidence interval [CI]: 10.9-14.0), 11.6\% (95\% CI: 10.0-13.1), and 4.9\% (95\% CI: 3.8-5.9), respectively. The prevalence rates of illicit opioids (1.8\%, 95\% CI: $1.2-2.5)$, cannabis $(1.2 \%, 95 \% \mathrm{CI}: 0.7-1.7)$, methamphetamine (1.1\%, 95\% CI: 0.6-1.6), methylphenidate $(2.5 \%, 95 \%$ CI: $1.7-3.2)$, and extramarital sex (5.5\%, 95\% CI: 4.5-6.6) over the last year were also estimated. Three latent classes were determined: 1) low risk; 2) cigarette and hookah smoker; and 3 ) high risk. It is worth mentioning that $3.7 \%$ of males and $0.4 \%$ of females were in the high risk group.

Conclusion: Subgrouping of college students showed that a considerable percentage of them, especially males, were classified into the high risk and cigarette and hookah smoker groups. Appropriate preventive measures that consider multiple different risky behaviors simultaneously are needed for this part of the population.

Keywords: alcohol drinking, sexual behavior, latent class analysis, risk behaviors, drug abuse, substance abuse

\section{Introduction}

Risky behavior means a "specific form of behavior, which is proven to be associated with increased susceptibility to a specific disease or ill-health". ${ }^{1}$ According to the report of the Youth Risk Behavior Surveillance in the US, ${ }^{2}$ tobacco and substance use and sexual behaviors that contribute to sexually transmitted infections, including extramarital sex, are priority health risky behaviors, which may interrupt development or cause considerable morbidity or mortality. ${ }^{3}$ Drug use, alcohol use, and sexual behaviors are responsible for $2 \%, 7 \%$, and $4 \%$, respectively, of the global disabilityadjusted life years among 15- to 24-year-old age groups. ${ }^{4}$

Community health can be considerably improved through controlling risky behaviors in young people, since $15 \cdot 5 \%$ of total disability-adjusted life years for all age groups are devoted to people aged 15-24 years. ${ }^{4}$

Determining subgroups of young people based on risky behaviors provides the opportunity for health service managers and policy makers to recognize people who have identical characteristics based on risky behavior patterns. ${ }^{5}$ 
To categorize individuals and have distinct groups, a person-centered analytic approach appears to be a useful and interesting statistical method. ${ }^{6}$ In order to identify distinct subgroups, latent class analysis (LCA) uses categorical and cross-sectional observed indicators to assign class memberships to individuals and yield unobserved (latent) classes of people in an attempt to arrive at the smallest number of latent classes. ${ }^{5,6}$

Detecting patterns of risky behaviors that young people are engaged in is necessary for considering intervention strategies. People who engage only in drug use, for instance, may be somewhat different from those who are involved with an array of other risky behaviors. ${ }^{7}$

There are a few studies that have used the LCA method to identify subgroups of risky behaviors among young people. In one of the studies among US college students that used LCA, subgroups of individuals were identified in their 4th year of college based on their patterns of seven substanceuse behaviors: extreme heavy episodic drinking, cigarette use, cigar/cigarillo/little cigar use, smokeless tobacco use, hookah use, marijuana use, and nonmedical prescription drug use. The researchers identified five classes defined by unique behavior patterns: 1) non/low users; 2) nonhookah tobacco users; 3) extreme heavy episodic drinking and marijuana users; 4) hookah and marijuana users; and 5) polysubstance users. Furthermore, some other variables were used as a covariate in the model. ${ }^{8}$ Another study in a public US university, which used LCA, examined behavior patterns in weight behaviors (diet and physical activity), substance use, sexual behavior, stress, and sleep among undergraduate students. The identified latent classes in this study were not the same between males and females. ${ }^{9}$

The present study used an LCA to investigate potential subgroups of college students based on their responses to a series of questions about risky behaviors. Drawing on the concepts of LCA, the present study proposed to determine the subgroups of students based on risky behaviors and assess the prevalence of risky behaviors in subgroups.

\section{Participants and methods Study design}

This study was carried out in October 2015 and November 2015. It was a cross-sectional study that was done through using multistage random sampling of 1,777 students from Tabriz University of Medical Sciences (TBZMED) located in north-west Iran and training them in almost all medical fields, with more than 7,000 undergraduate and 1,000 postgraduate students. First, schools were considered as strata, and all of them were involved in the study. Second, the field of study was considered as second stratum, and then, in proportion to the number of students in each field of study, two to four classes were randomly selected as clusters. Students were asked to complete a questionnaire that was distributed at the beginning of each class. The students had specific time slots to fill out the questionnaires. To ensure a high level of privacy protection of the study, all the students of the selected class were invited to complete the questionnaire and all the filled questionnaires were subsequently placed in an envelope, which was not attributable/identifiable to the given student.

\section{Study tools}

A self-administered questionnaire was tested on 38 college students twice (time interval 7 days) in one of the schools, which is affiliated to TBZMED. The aim of the pilot study was to assess the feasibility and reliability of the questionnaire. Afterward, the study tool was modified using these pilot experiences.

To ensure a high level of privacy protection and to decrease social desirability bias among the participants, an anonymous questionnaire with only one demographic variable (sex) was used in the study. Using this type of questionnaire confined our ability for assessing the role of the covariates, but it ensured accurate subgrouping of the subjects through decreasing social desirability bias, which is the main goal in the LCA method. Therefore, to assess risky behaviors, eight dichotomous variables were used and participants gave yes/no answer to them. The variables were opium or its residue, heroin, or heroin crack use (illicit opioids); ${ }^{10}$ cannabis use; methamphetamine, methylphenidate (Ritalin); and extramarital sex; ie, any sexual intercourse between two people that leads to an orgasm. The least frequency, ie, one, of these substances or behaviors during the last year was considered as a risky behavior. However, cigarette smoking ( $\geq$ ten cigarettes during the last year), hookah use ( $\geq 1$ time/mo during the last year), and alcohol use ( $\geq 1$ time/mo during the last year) were differently defined as risky behaviors. It is worth mentioning that in the present study, the most common illicit drugs in Iran were assessed and the uncommon ones such as cocaine were excluded.

Face validity was assessed by asking experts to scrutinize the questions. We also asked the participants to use an alias to maintain anonymity in reliability assessment. They wrote an alias on the questionnaire for the first time, and when we invited them to fill out the questionnaire for the second time, we asked them to use the same alias. In this way, we paired the questionnaires that belonged together. Kappa statistics 
were used to assess the reliability of the questionnaire. Eight kappa statistics were estimated since there were eight variables in the questionnaire to assess different risky behaviors. The mean of these eight kappa statistics was $64 \%$, which is considered as a substantial agreement. ${ }^{11}$

\section{Ethical considerations}

The ethics committees of TBZMED and Tehran University of Medical Sciences (TUMS) approved the study protocol and its questionnaire. Furthermore, verbal consent was obtained from the participants.

\section{Statistical analysis and sample size}

So as to analyze data, LCA was used for both sexes. LCA is a latent categorical variable's model and traditionally classifies people with similar characteristics. In addition to the measurement error, it seeks to identify if correlations between observed variables can be explained by latent variables.

By using a concept similar to the calculation of $\chi^{2}$, the best model is selected by LCA using $G^{2}$ statistics. In the present study, this is done by calculating various iterations for the number of identified classes of the latent variable and comparing the frequencies of the observed response patterns with the expected ones. Moreover, model selection is done by Akaike information criterion (AIC) and Bayesian information criterion (BIC), which are calculated based on $G^{2}$ statistics. $^{5}$

For all information criteria, a smaller value represents a more optimal balance of model fit and parsimony; thus, a model with the minimum AIC or BIC might be selected. When the degrees of freedom are large, the reference distribution for $G^{2}$ statistics is not known, so we do not report $P$-values for tests of model fit. ${ }^{5}$ Item-response probabilities $>0.5$ in each class were highlighted to facilitate interpretation and were used in labeling the classes, so that classes with no probabilities $>0.5$, probabilities $>0.5$ for cigarette smoking and hookah use, and probabilities $>0.5$ for more than two variables were labeled as low risk, cigarette and hookah smoker, and high risk, respectively. Eight dichotomous observable variables were applied to assess risky behaviors using the LCA method. These variables were cigarette smoking, hookah use, alcohol consumption, illicit opioids, cannabis use, methamphetamine use, methylphenidate use, and having extramarital sex. All the analyses of the study were done by using PROC LCA in SAS 9.2 software (SAS Institute Inc., Cary, NC, USA). The most important information is presented here, but the more detailed information was discussed by Collins and Lanza. ${ }^{5}$

The sample size was calculated by using PS software (Version 3.1.2; Department of Statistics, Vanderbilt University, Nashville, TN, USA) based on one-sample proportion for extramarital sex variable. ${ }^{12}$ The minimum sample size of 1,142 subjects was calculated in order to ensure desired precision of $2 \%$ and estimated true proportion of $13 \%$ and to fulfill $95 \%$ confidence level. Also, the minimum sample size of 1,000 subjects was suggested by Collins and Lanza ${ }^{5}$ in studies in which the LCA method is applied. Therefore, $\sim 635$ subjects were added to the calculated minimum sample size to ensure more accurate LCA for the present study $(\mathrm{n}=1,777)$.

\section{Results}

Out of the 1,777 invited individuals, 1,730 agreed to participate in this study (response rate 97.3\%). Approximately $40.7 \%$ of participants were males. The prevalence of risky behaviors is presented by sex in Table 1 . Smoking at least ten cigarettes $(12.4 \%), \geq 1$ time/mo hookah use $(11.6 \%)$, extramarital sex (5.5\%), and $\geq 1$ time/mo alcohol use (4.9\%) during the last year were more prevalent than other studied

Table I Percentages of students responding yes to questions about risky behaviors

\begin{tabular}{|c|c|c|c|c|c|c|c|c|c|}
\hline \multirow[t]{2}{*}{ Items $^{a}$} & \multicolumn{3}{|c|}{ Male $(n=705)$} & \multicolumn{3}{|c|}{ Female $(n=I, 025)$} & \multicolumn{3}{|c|}{ Total $(n=I, 730)$} \\
\hline & $\mathbf{n}$ & $\%$ & $95 \% \mathrm{Cl}$ & $\mathbf{n}$ & $\%$ & $95 \% \mathrm{Cl}$ & $\mathbf{n}$ & $\%$ & $95 \% \mathrm{Cl}$ \\
\hline Cigarette smoking & 146 & 20.7 & I7.7-23.7 & 69 & 6.7 & $5.2-8.3$ & 215 & 12.4 & $10.9-14.0$ \\
\hline Hookah use & 150 & 21.3 & $18.2-24.3$ & 50 & 4.9 & $3.6-6.2$ & 200 & 11.6 & $10.0-13.1$ \\
\hline Alcohol use & 71 & 10.1 & $7.8-12.3$ & 13 & 1.3 & $0.6-1.9$ & 84 & 4.9 & $3.8-5.9$ \\
\hline Illicit drugs & 36 & 5.1 & $3.4-6.7$ & 5 & 0.5 & $0.16-1.1$ & $4 I$ & 2.4 & $1.6-3.0$ \\
\hline Illicit opioids & 29 & 4.1 & $2.6-5.6$ & 3 & 0.3 & $0.06-0.8$ & 32 & 1.8 & $1.2-2.5$ \\
\hline Cannabis & 18 & 2.6 & $1.4-3.7$ & 3 & 0.3 & $0.06-0.8$ & 21 & $\mathrm{I} .2$ & $0.7-I .70$ \\
\hline Methamphetamine & 16 & 2.3 & $1.2-3.4$ & 3 & 0.3 & $0.06-0.8$ & 19 & $\mathrm{I} . \mathrm{I}$ & $0.6-1.6$ \\
\hline Methylphenidate & 29 & 4.1 & $2.6-5.6$ & 14 & $\mathrm{I} .4$ & $0.6-2.1$ & 43 & 2.5 & $1.7-3.2$ \\
\hline Extramarital sex & 72 & 10.2 & $8.0-12.4$ & 24 & 2.3 & $1.4-3.3$ & 96 & 5.5 & $4.5-6.6$ \\
\hline
\end{tabular}

Note: "The time period of all items in the table is "last year".

Abbreviation: $\mathrm{Cl}$, confidence interval. 
Table 2 Comparison of LCA models with different latent classes based on model selection statistics

\begin{tabular}{|c|c|c|c|c|c|c|}
\hline $\begin{array}{l}\text { Number of } \\
\text { latent classes }\end{array}$ & $\begin{array}{l}\text { Number of parameters } \\
\text { estimated }\end{array}$ & $G^{2}$ & $d f$ & AIC & BIC & $\begin{array}{l}\text { Maximum log- } \\
\text { likelihood }\end{array}$ \\
\hline I & 16 & I,092.20 & 495 & I, I24.20 & $1,211.49$ & $-2,360.90$ \\
\hline 2 & 34 & $326.4 I$ & 477 & 394.41 & 579.91 & $-1,978.01$ \\
\hline 3 & 52 & 187.77 & 459 & 291.77 & 575.47 & $-1,908.69$ \\
\hline 4 & 70 & 160.10 & $44 I$ & 300.10 & 682.01 & $-1,894.85$ \\
\hline 5 & 88 & 135.97 & 423 & 311.97 & 792.08 & $-1,882.79$ \\
\hline 6 & 106 & 121.87 & 405 & 333.87 & 912.19 & $-1,875.74$ \\
\hline 7 & 124 & 105.24 & 387 & 353.24 & I,029.77 & $-1,867.43$ \\
\hline 8 & 142 & 89.84 & 369 & 373.84 & $\mathrm{I}, \mathrm{I} 48.57$ & $-1,859.72$ \\
\hline 9 & 160 & 87.50 & 351 & 407.50 & I,280.44 & $-1,858.56$ \\
\hline 10 & 178 & 82.21 & 333 & 438.21 & I,409.36 & $-|, 855.9|$ \\
\hline
\end{tabular}

Abbreviations: LCA, latent class analysis; AIC, Akaike information criterion; BIC, Bayesian information criterion.

risky behaviors. It was found that the prevalence of risky behaviors in the last year was more common among males compared to females.

Considering eight dichotomous indicators indicated that there were 256 possible response patterns ( patterns $=2^{\mathrm{n}}$ ). The researchers tried to fit LCA models with one to ten classes. $G^{2}$, AIC, and BIC of each LCA model are given in Table 2. In accordance with the LCA model selection criteria, three latent class models were deemed to be appropriate. These findings are presented in Tables 3 and 4, which contain prevalence of latent classes and item-response probabilities for males and females, respectively.

Row 1 of Tables 3 and 4 shows the probability of belonging to each latent class. It was found that almost $78.8 \%$ of males were at low risk class and $3.7 \%$ of them were at high risk class. Results from the females showed that $\sim 95 \%$ of them were at low risk class and $0.4 \%$ were at high risk class. Tables 3 and 4 show the probabilities of responding with a

Table 3 The three latent classes model of risky behaviors among male students

\begin{tabular}{|c|c|c|c|}
\hline & \multicolumn{3}{|c|}{ Latent classes } \\
\hline & $\begin{array}{l}\text { Low } \\
\text { risk }\end{array}$ & $\begin{array}{l}\text { Cigarette and } \\
\text { hookah smoker }\end{array}$ & $\begin{array}{l}\text { High } \\
\text { risk }\end{array}$ \\
\hline Latent class prevalence & 0.788 & 0.175 & 0.037 \\
\hline Item-response probabilities ${ }^{\mathrm{a}, \mathrm{b}}$ & \multicolumn{3}{|c|}{ Probability of a yes response } \\
\hline Cigarette smoking & 0.050 & 0.830 & 0.585 \\
\hline Hookah use & 0.067 & 0.759 & 0.717 \\
\hline Alcohol & 0.012 & 0.379 & 0.654 \\
\hline Illicit opioids & 0.000 & 0.069 & 0.778 \\
\hline Cannabis & 0.001 & 0.009 & 0.601 \\
\hline Methamphetamine & 0.001 & 0.000 & 0.570 \\
\hline Methylphenidate & 0.001 & 0.092 & 0.634 \\
\hline Extramarital sex & 0.030 & 0.333 & 0.520 \\
\hline
\end{tabular}

"yes" response to each risky behavior. The results of the probabilities are used to explain and determine different latent classes.

In high risk class, the probability of responding with a yes response to the risky behaviors was high for all the risky behaviors among males; however, this probability was high for only some of the risky behaviors among females. Additionally, the probability of reporting all the studied risky behaviors was high among the males of high risk class, whereas smoking, opium, methamphetamine, and methylphenidate had only high probability of reporting among the females of this class. The probability of engaging in risky behaviors was very low for both sexes in low risk class.

One other latent class, cigarette and hookah smoker, showcased a different pattern of risky behaviors such that the probability of engaging in cigarette smoking and hookah use was high among males and females of this class.

Table 4 The three latent classes model of risky behaviors among female students

\begin{tabular}{|c|c|c|c|}
\hline & \multicolumn{3}{|c|}{ Latent classes } \\
\hline & $\begin{array}{l}\text { Low } \\
\text { risk }\end{array}$ & $\begin{array}{l}\text { Cigarette and } \\
\text { hookah smoker }\end{array}$ & $\begin{array}{l}\text { High } \\
\text { risk }\end{array}$ \\
\hline Latent class prevalence & 0.954 & 0.041 & 0.004 \\
\hline Item-response probabilities ${ }^{\mathrm{a}, \mathrm{b}}$ & \multicolumn{3}{|c|}{ Probability of a yes response } \\
\hline Cigarette smoking & 0.039 & 0.645 & 0.7 I I \\
\hline Hookah use & 0.023 & 0.626 & 0.227 \\
\hline Alcohol & 0.003 & 0.234 & 0.003 \\
\hline Illicit opioids & 0.000 & 0.000 & 0.629 \\
\hline Cannabis & 0.000 & 0.023 & 0.419 \\
\hline Methamphetamine & 0.000 & 0.000 & 0.629 \\
\hline Methylphenidate & 0.010 & 0.019 & 0.697 \\
\hline Extramarital sex & 0.014 & 0.180 & 0.434 \\
\hline
\end{tabular}




\section{Discussion}

Smoking at least ten cigarettes during the last year was the most common risky behavior, with a prevalence of $12.4 \%$ (males: 20.7\%; females: 6.7\%), and methamphetamine use more than or equal to once during the last year was the least common at $1.1 \%$ (males: $2.3 \%$; females: $0.3 \%$ ). The findings suggest that these risky behaviors are more prevalent in males than females. A study on prevalence of smoking among university students of 23 countries reported that the frequency of smoking varies from $14 \%$ in Thailand to $47 \%$ in Portugal. ${ }^{13}$ In addition, epidemiologic studies have shown a considerable variety regarding prevalence of smoking among student population of various Arabic and eastern Mediterranean countries. ${ }^{14-19}$ A meta-analysis in Iran found that smoking prevalence varies from $13.4 \%$ to $39.9 \%$ among males and $0.7 \%$ to $25.5 \%$ among female students. ${ }^{20}$ This meta-analysis also indicated that prevalence of smoking among Iranian male (19.8\% [17.7-21.9]) and female $\left(2.2 \%\right.$ [1.4-3.02]) students is considerable. ${ }^{20}$ This broad range may be related to different definitions of the term "smoker", the differences in age of study samples, and location of studies. Another study on Iranian college students also found decreasing trend in smoking prevalence. $^{21}$

The present study also found that the last year prevalence of $\geq 1$ time/mo hookah use was $11.6 \%$ and was more prevalent in males $(21.3 \%)$ than females $(4.9 \%)$. A study in New York showed that lifetime prevalence of hookah use increased from $29 \%$ to $45 \%$ among the first-year students one year (after 12 months). ${ }^{22}$ According to two Iranian national health surveys, conducted in 1991 and 1999, hookah smoking is increasing among 15-24-year-old males and females. ${ }^{23}$ However, one study involving medical university students in Tabriz reported that the prevalence of hookah use at least once per month is $5.1 \%$ (males: $9.3 \%$; females: $2.4 \%$ ), which is lower than the estimation of the present study. ${ }^{24}$ Also, one study involving medical university students of Tehran found that lifetime, last year, and last month prevalence of hookah smoking was $26.6 \%$ (males: $42.8 \%$; females: $19.4 \%$ ), $17.8 \%$ (males: $29.7 \%$; females: $12.5 \%$ ), and $8.9 \%$ (males: $15.8 \%$; females: $5.9 \%$ ), respectively. ${ }^{25}$

Concerning alcohol consumption ( $\geq 1$ time/mo), this study indicates a last year prevalence of $4.9 \%$ overall, with the behavior being more common in males than females $(10.1 \%$ vs $1.3 \%)$. The last year and last month prevalence rates of alcohol consumption among college students were reported to be $81 \%-88 \%$ and $3 \%-4.8 \%$, respectively, based on Monitoring the Future study in the US. ${ }^{26}$ A review on the prevalence of alcohol consumption among students in
Iran showed that the last month prevalence rates of alcohol consumption were $10.2 \%-30.4 \%$ for males and $1.8 \%-2.1 \%$ for females. ${ }^{27} \mathrm{~A}$ previous anonymous study demonstrated that last year alcohol consumption among Iranian college students was again more common in males (13.4\%) compared to females $(2.23 \%))^{12}$

The prevalence of past year illicit opioid use was estimated at $1.8 \%$ and was, again, more prevalent among males than females ( $4.1 \%$ vs $0.3 \%)$. These results are somewhat similar to previously published studies; a review on the prevalence of substance use among Iranian students showed that lifetime prevalence of opium use ranged between $7.8 \%$ and $31.8 \%$ for males and $0 \%$ and $5 \%$ for females. ${ }^{27}$ Last month prevalence of opium use ranged from $7.1 \%$ to $24.5 \%$ for males and $0 \%$ to $3.2 \%$ for females. This review also found that a higher percentage of males demonstrated lifetime use of heroin $(0 \%-2.1 \%)$ compared to females $(0 \%-0.6 \%) .{ }^{27}$ Last month heroin use had a similar pattern with regard to sex (males: 0\%-1.8\%; females: 0\%-0.4\%). ${ }^{27}$

This study also showed last year prevalence of cannabis use to be $1.2 \%$, which was higher in males than females ( $2.6 \%$ vs $0.3 \%)$. According to Monitoring the Future study, the trend of cannabis use among college students is increasing, with a noted rise from $29.8 \%$ in 1991 to $35.7 \%$ in $2008 .{ }^{26}$ Based on the report of European School Survey Project on Alcohol and Other Drugs in 2011, use of cannabis in the past 12 months was reported, on average, by $15 \%$ of males and $11 \%$ of females ( $13 \%$ of all students) in 36 European countries. ${ }^{28}$ Lifetime prevalence of cannabis use among Iranian college students is reported to range from $6.6 \%$ to $24.7 \%$ and $0 \%$ to $2.3 \%$ for males and females, respectively; ${ }^{27}$ The past month prevalence of cannabis use ranged from $1.7 \%$ to $8.8 \%$ (males) and $0 \%$ to $0.6 \%$ (females).

This study demonstrated that last year prevalence of methamphetamine use to be $1.1 \%$, which was, again, more common in males (2.3\% vs $0.3 \%$ ). Based on Monitoring the Future study, last year prevalence of methamphetamine use among college students followed a decreasing trend, changing from $3.3 \%$ in 1999 to $0.5 \%$ in $2008 .{ }^{26}$ Two studies on Iranian college students found that last year prevalence of methamphetamine use ranged from $1 \%$ to $8.8 \% .^{29,30}$

In the present study, last year prevalence of methylphenidate use was reported by $2.5 \%$ of students and its prevalence was threefold in males compared to females ( $4.1 \%$ vs $1.4 \%)$. Results from Monitoring the Future study indicate a slightly higher prevalence of last year methylphenidate use among college students, though this decreased from 5.7\% in 2002 to $3.2 \%$ in $2008 .{ }^{26}$ Another study on Iranian college students found the prevalence of methylphenidate use, at least three 
times a week for the last month or last year, to be $4.91 \%$, which was, again, more common in males (7.34\% vs 3.84\%). ${ }^{29}$

In our study, engaging in extramarital sex during the past year was reported by $5.5 \%$ of the participants. The prevalence was five times higher in males than females (10.2\% vs $2.3 \%$ ). According to Youth Risk Behavior Surveillance study in the US, $\sim 47.4 \%$ of students had sexual experience at least once in their lifetime and $33.7 \%$ had sexual experience in the last 3 months. ${ }^{31} \mathrm{~A}$ study including Chinese college students found that $12.6 \%$ of students reported having extramarital heterosexual intercourse during the last year and males were more at risk for this behavior than females $(15.4 \%$ vs $8.6 \%) .{ }^{32}$ A similar anonymous study among Iranian College students found that the past year prevalence of extramarital sex was $10.3 \%$ for males and $1.4 \%$ for females. ${ }^{12}$

A useful method of prevention is consideration of concurrent high-risk behaviors. Various studies have proved that engaging in one risky behavior is related with involvement in other high-risk behaviors. ${ }^{33}$ Some studies have assessed the concurrent engagement in cigarette and hookah smoking, ${ }^{34}$ cigarette smoking and alcohol consumption, ${ }^{35}$ cigarette smoking and substance use, ${ }^{36}$ and sexual risky behaviors with substance use and alcohol. ${ }^{37}$ Having considered all the most important aspects, the present study examined risky behaviors using different approaches and identified three latent classes for both sexes.

The three latent classes are: 1) low risk; 2) cigarette and hookah smoker; and 3) high risk. According to the findings of this study, the prevalence rates of low risk, cigarette and hookah smoker, and high-risk classes were 78\%, 17\%, and $3.7 \%$ for males and $95 \%, 4.1 \%$, and $0.4 \%$ for females, respectively. To the best of our knowledge, the LCA method was mainly used on high school students, while the present study has been carried out on college students. Despite the differences between them, including substances and study samples, the comparison seems to be valuable. Some researchers conducted a study on 13,935 high school students in Columbia and found that there were four classes for substance use and sexual risk. The prevalence rates of nonusers, alcohol experimenters, occasional polysubstance users, and frequent polysubstance users in substance-use classes were $27 \%, 38 \%, 23 \%$ and $13 \%$, respectively. Also, the prevalence rates of abstainers, monogamous partner, low-frequency multipartner, and high-frequency multipartner in sexual risk classes were $53 \%, 15 \%, 18 \%$, and $14 \%$, respectively. Notably, substance-use class showed an independent strong association with sexual behavior after controlling for confounding demographic variables. ${ }^{38}$
Another study using data from the California Healthy Kids Survey of seventh, ninth, and eleventh graders was done to recognize latent classes of alcohol, tobacco, and marijuana use among 418,702 subjects. ${ }^{39}$ The four classes including nonusers, alcohol experimenters, mild polysubstance users, and frequent polysubstance users were determined. The most prevalent and least prevalent classes were nonusers (61\%) and frequent polysubstance users $(6.9 \%)$, respectively. ${ }^{40}$ Moreover, another study that was conducted on a nationally representative school-based cohort of the US also found four classes: non-users (59\%), predominant alcohol users (23\%), predominant marijuana users $(11 \%)$, and predominant poly-substance users $(8 \%){ }^{41}$ The lower prevalence of high risk class in the present study may be related to religious beliefs of Iranian families and legal forbiddance of alcohol and drug use.

The percentage of males $(3.7 \%)$ in the high risk class was higher than that of females $(0.4 \%)$. A similar trend was noted with cigarette and hookah smoker class (males: 17.5\%; females: 4.1\%). This sex pattern regarding risky behaviors has been reported from other studies, as well. ${ }^{42,43}$ The probability of engaging was high for all risky behaviors among males of high risk group, but females in this group had a high probability of using illicit opioids, methamphetamine, and methylphenidate. A study among adolescents of California reported similar findings and found that tendency for polysubstance use is higher in males than in females. ${ }^{39}$ The probability of engaging in risky behaviors was similar for both sexes in cigarette and hookah smoker class among a group of Iranian college students. ${ }^{44}$ Also, as seen in Table 4, cannabis use, extramarital sex, and alcohol use had few roles (probability $<0.5$ ) in grouping of Iranian female students in our study. This may be considered in prevention programs.

Moreover, the findings suggested that mental health problems among adolescents are more prevalent in polysubstance users than in cannabis or alcohol users. Furthermore, predictors of comorbid mental health/polysubstance-use disorders differ from those of alcohol/cannabis-use disorders and are detectable during adolescence. ${ }^{45}$

Some sociocultural causes may play a great role in a person's decision to be a polysubstance user. These causes may be divided into social and cultural ones. In terms of social causes, some studies have demonstrated that polysubstance dependence is most enjoyable for young adults..$^{39,45}$ A study carried on population aged 12-25 years showed that young adults constitute about half of the nation's illicit drug users. Also, $50 \%$ of illicit drug users were engaged before 
the 12 th grade. This might be due to social expectations of peers, peer pressure, or a way to soothe their emotions. Also, it can be claimed that media, as a cultural factor, affects young adults in our culture today. There are several "role models" who have major drug problems through promoting a lifestyle of partying and abusing drugs. This gives the youths the idea that taking many different substances would not have any consequences. This assumption leads to a large number of youths who use substances. Notably, media in Iran plays a main role in coping with risky behaviors, especially substances. ${ }^{39}$

Another study assessed individual and social predictors of poly-substance use among Italian substance-dependent adolescents. The authors found that the mean age of participants with polysubstance dependence was significantly lower than others. Unemployment, divorce, childhood emotional, aggression, physical neglect, and impulsivity were significantly prevalent among polysubstance users. Also, prevalence of suicide attempt, self-mutilation, and exhibited aggressive behavior were significantly higher in polysubstance users. ${ }^{46}$

The results of the present study indicated that specific male students (high risk class) used a combination of illegal drugs together. Also, female students in the high risk group used almost all illegal drugs concurrently. According to biological, psychological, and sociocultural causes of the polysubstance use, the concurrent use of illegal drugs among students is expected.

The strengths of this study were its large representative sample and high response rate, both of which increase the generalizability of the findings. However, the present work relied on self-report data from college students, and underreporting of some risky behaviors is expected, although the participants were assured of the anonymity of the questionnaires.

\section{Conclusion}

The present study reported the prevalence of risky behaviors among college students of TBZMED. Furthermore, our study demonstrates frequent concurrent occurrence of risky behaviors by subgrouping of students into three classes for both sexes. The findings indicate that a considerable percentage of students are in high risk and cigarette and hookah smoker classes, which underlines the necessity of preventive measures for this part of the population. It should be noted that longitudinal studies are valuable to determine incidence rate and change of patterns in these behaviors and their correlates. The findings of the present study could be useful for planning and evaluating preventive measures that consider multiple different risky behaviors simultaneously.

\section{Acknowledgments}

This article is a part of the $\mathrm{PhD}$ thesis of Epidemiology supported by TUMS and TBZMED. We would like to thank Deputy of Research of TUMS and TBZMED for financial support.

\section{Disclosure}

The authors report no conflicts of interest in this work. The authors alone are responsible for the content and writing of the paper.

\section{References}

1. Kickbusch I, Nutbeam D. Health Promotion Glossary. Geneva: World Health Organization; 1998.

2. Kann L, Kinchen S, Shanklin SL, et al. Youth risk behavior surveillanceUnited States, 2013. MMWR Surveill Summ. 2014;63(suppl 4):1-168.

3. De Guzman M, Bosch K. High-Risk Behaviors among Youth. Lincoln, NE: University of Nebraska-Lincoln Extension, Institute of Agriculture and Natural Resources; 2007.

4. Gore FM, Bloem PJ, Patton GC, et al. Global burden of disease in young people aged 10-24 years: a systematic analysis. Lancet. 2011;377(9783): 2093-2102.

5. Collins LM, Lanza ST. Latent Class and Latent Transition Analysis: with Applications in the Social, Behavioral, and Health Sciences. Vol. 718. New York City, NY: John Wiley \& Sons; 2013.

6. Muthén B, Muthén LK. Integrating person-centered and variablecentered analyses: growth mixture modeling with latent trajectory classes. Alcohol Clin Exp Res. 2000;24(6):882-891.

7. Moffitt TE. Adolescence-limited and life-course-persistent antisocial behavior: a developmental taxonomy. Psychol Rev. 1993;100(4): 674-701.

8. Evans-Polce R, Lanza S, Maggs J. Heterogeneity of alcohol, tobacco, and other substance use behaviors in US college students: a latent class analysis. Addict Behav. 2016;53(1):80-85.

9. Laska MN, Pasch KE, Lust K, Story M, Ehlinger E. Latent class analysis of lifestyle characteristics and health risk behaviors among college youth. Prev Sci. 2009;10(4):376-386.

10. Farhoudian A, Sadeghi M, Vishteh HRK, Moazen B, Fekri M, RahimiMovaghar A. Component analysis of Iranian crack; a newly abused narcotic substance in Iran. Iran J Pharm Res. 2014;13(1):337.

11. Landis JR, Koch GG. The measurement of observer agreement for categorical data. Biometrics. 1977;33(1):159-174.

12. Sheikhzadeh K, Baneshi MR, Afshari M, Haghdoost AA. Comparing direct, network scale-up, and proxy respondent methods in estimating risky behaviors among collegians. J Subst Use. 2016;21(1):9-13.

13. Steptoe A, Wardle J, Cui W, et al. An international comparison of tobacco smoking, beliefs and risk awareness in university students from 23 countries. Addiction. 2002;97(12):1561-1571.

14. Almerie MQ, Matar H, Salam M, et al. Cigarettes \& waterpipe smoking among medical students in Syria: a cross-sectional study. Int J Tuberc Lung Dis. 2008;12(9):1085.

15. Kofahi MM, Haddad LG. Perceptions of lung cancer and smoking among college students in Jordan. J Transcult Nurs. 2005;16(3):245-254.

16. Saatci E, Inan S, Bozdemir N, Akpinar E, Ergun G. Predictors of smoking behavior of first year university students: questionnaire survey. Croat Med J. 2004;45(1):76-79.

17. Al-Turki YA. Smoking habits among medical students in Central Saudi Arabia. Saudi Med J. 2006;27(5):700-703. 
18. Khader Y, Alsadi A. Smoking habits among university students in Jordan: prevalence and associated factors. East Mediterr Health J. 2008; 14(4):897-904.

19. Ramakrishna G, Sarma PS, Thankappan K. Tobacco use among medical students in Orissa. Natl Med J India. 2005;18(6):285.

20. Haghdoost AA, Moosazadeh M. The prevalence of cigarette smoking among students of Iran's universities: a systematic review and metaanalysis. J Res Med Sci. 2013;18(8):717-725.

21. Amin-Esmaeili M, Rahimi-Movaghar A, Yunesian M, Sahimi-Izadian E, Moinolghorabaei M. Trend of smoking among students of Tehran University of Medical Sciences: results from four consecutive surveys from 2006 to 2009. Med J Islam Repub Iran. 2013;27(4):168-178.

22. Fielder RL, Carey KB, Carey MP. Prevalence, frequency, and initiation of hookah tobacco smoking among first-year female college students: a one-year longitudinal study. Addict Behav. 2012;37(2):221-224.

23. Mohammad K, Nourbala A-A, Madjdzadeh R, Karimlou M. Trend of smoking prevalence in Iran from 1991 to 1999 based on two national health survey. Hakim. 2001;3(4):290-294.

24. MohammadPoorasl A, Abbasi Ghahramanloo A, Allahverdipour H, Modaresi Esfeh J. Prevalence of Hookah smoking in relation to religiosity and familial support in college students of Tabriz, northwest of Iran. J Res Health Sci. 2014;14(4):268-271.

25. Abbasi-Ghahramanloo A, Rahimi-Movaghar A, Zeraati H, Safiri S, Fotouhi A. Prevalence of Hookah Smoking and Its Related Factors Among Students of Tehran University of Medical Sciences, 2012-2013. Iranian Journal of Psychiatry and Behavioral Sciences. Epub 2016.

26. Johnston LD. Monitoring the Future: National Survey Results on Drug Use, 1975-2008: Volume II: College Students and Adults Ages 19-50. Collingdale, PA: DIANe Publishing; 2010.

27. Rahimi-Movaghar A, Sahimi-Izadian E, Younesian M. The drug use situation in university students in Iran: a literature review. Health Monitor (Payesh). 2006;5(2):83-104.

28. Hibell B, Guttormsson U, Ahlström S, et al. The 2011 ESPAD Report. Substance Use among Students in 36 European Countries. Stockholm, Sweden: The Swedish Council for Information on Alcohol and Other Drugs; 2012.

29. Abbasi-Ghahramanloo A, Fotouhi A, Zeraati H, Rahimi-Movaghar A. Prescription drugs, alcohol, and illicit substance use and their correlations among medical sciences students in Iran. Int J High Risk Behav Addict. 2015;4(1):e21945.

30. Heydarabadi AB, Ramezankhani A, Barekati H, et al. Prevalence of substance abuse among dormitory students of Shahid Beheshti University of Medical Sciences, Tehran, Iran. Int J High Risk Behav Addict. 2015; 4(2):e22350.

31. Eaton DK, Kann L, Kinchen S, et al. Youth risk behavior surveillanceUnited States, 2011. MMWR Surveill Summ. 2012;61(4):1-162.
32. Chi X, Yu L, Winter S. Prevalence and correlates of sexual behaviors among university students: a study in Hefei, China. BMC Public Health. 2012;12(1):972.

33. Brooks FM, Magnusson J, Spencer N, Morgan A. Adolescent multiple risk behaviour: an asset approach to the role of family, school and community. J Public Health. 2012;34(suppl 1):i48-i56.

34. PrimackBA, Sidani J, Agarwal AA, Shadel WG, Donny EC, Eissenberg TE. Prevalence of and associations with waterpipe tobacco smoking among US university students. Ann Behav Med. 2008;36(1):81-86.

35. Reed MB, Wang R, Shillington AM, Clapp JD, Lange JE. The relationship between alcohol use and cigarette smoking in a sample of undergraduate college students. Addict Behav. 2007;32(3):449-464.

36. Terry-McElrath YM, O’Malley PM, Johnston LD. Energy drinks, soft drinks, and substance use among United States secondary school students. J Addict Med. 2013;8(1):6-13.

37. Woodford MR, Krentzman AR, Gattis MN. Alcohol and drug use among sexual minority college students and their heterosexual counterparts: the effects of experiencing and witnessing incivility and hostility on campus. Subst Abuse Rehabil. 2012;3:11-23.

38. Connell CM, Gilreath TD, Hansen NB. A multiprocess latent class analysis of the co-occurrence of substance use and sexual risk behavior among adolescents. J Stud Alcohol Drugs. 2009;70(6):943-951.

39. Troncale J. Understanding the Dynamics of Polysubstance Dependence. USA: Addiction Professional; 2004.

40. Gilreath TD, Astor RA, Estrada JN, Johnson RM, Benbenishty R, Unger JB. Substance use among adolescents in California: a latent class analysis. Subst Use Misuse. 2014;49(1-2):116-123.

41. Conway KP, Vullo GC, Nichter B, et al. Prevalence and patterns of polysubstance use in a nationally representative sample of 10th graders in the United States. J Adolesc Health. 2013;52(6):716-723.

42. Sutfin EL, Song EY, Reboussin BA, Wolfson M. What are young adults smoking in their hookahs? A latent class analysis of substances smoked. Addict Behav. 2014;39(7):1191-1196.

43. Carlson RG, Nahhas RW, Daniulaityte R, Martins SS, Li L, Falck R. Latent class analysis of non-opioid dependent illegal pharmaceutical opioid users in Ohio. Drug Alcohol Depend. 2014;134(1):259-266.

44. MohammadPoorasl A, Ghahramanloo AA, Allahverdipour H. Risktaking behaviors and subgrouping of college students a latent class analysis. Am J Mens Health. 2013;7(6):475-481.

45. Salom CL, Betts KS, Williams GM, Najman JM, Alati R. Predictors of comorbid polysubstance use and mental health disorders in young adults - a latent class analysis. Addiction. 2016;111(1):156-164.

46. Martinotti G, Carli V, Tedeschi D, et al. Mono-and polysubstance dependent subjects differ on social factors, childhood trauma, personality, suicidal behaviour, and comorbid Axis I diagnoses. Addict Behav. 2009; 34(9):790-793
Neuropsychiatric Disease and Treatment

\section{Publish your work in this journal}

Neuropsychiatric Disease and Treatment is an international, peerreviewed journal of clinical therapeutics and pharmacology focusing on concise rapid reporting of clinical or pre-clinical studies on a range of neuropsychiatric and neurological disorders. This journal is indexed on PubMed Central, the 'PsycINFO' database and CAS,

\section{Dovepress}

and is the official journal of The International Neuropsychiatric Association (INA). The manuscript management system is completely online and includes a very quick and fair peer-review system, which is all easy to use. Visit http://www.dovepress.com/testimonials.php to read real quotes from published authors. 